\title{
RECURRENT SPONTANEOUS ABORTION AND MALE FACTORS: AN OVERVIEW
}

\author{
Syed Nazar Imam¹, Sami Awda Algaidi², Zarin Rahman³
}

${ }_{1}^{1}$ Assistant Professor, Department of Anatomy, College of Medicine, Taibah University, Saudi Arabia.

${ }^{2}$ Associate Professor, Department of Anatomy, College of Medicine, Taibah University, Saudi Arabia.

${ }^{3}$ Professor, Department of Obstetrics \& Gynaecology, National Medical College, Birganj, Nepal.

\section{ABSTRACT}

Recurrent miscarriage is three or more consecutive pregnancy loss before 20 weeks of gestation. Despite detailed investigation of couples experiencing RSA in 40 to $50 \%$ of cases, the aetiology cannot be ascertained and are termed Idiopathic Recurrent Spontaneous Abortions (iRSA).

\section{DISCUSSION}

In the clinical investigation of male partner of iRSA, semen analysis detailing the sperm parameters do not always reveal significant information that could assist the clinician in patient's treatment. Due to limited predictive potential of semen analysis, new markers with better diagnostic and prognostic characteristic and ability to efficiently predict adverse reproductive events are being investigated. The findings of these studies have reported oxidative stress associated with sperm DNA damage as a leading cause for lower conception rate after assisted conception techniques. These findings have also provided a new direction to the studies investigating molecular markers as free radicals, antioxidants and sperm DNA fragmentation. It has been suggested that these markers are more reliable than semen analysis in male infertility cases including male partners of couples experiencing iRSA. Further, these recent studies also suggest that oxidative stress and sperm DNA integrity may offer better potential to predict sperm reproductive capacity.

\section{CONCLUSION}

This review provides an in-depth understanding of iRSA, its causative factors, the clinical findings and the most preferred therapeutics that could assist to improve the pregnancy outcome in such cases.

\section{KEYWORDS}

Infertility, Recurrent Spontaneous Abortions, Sperm DNA Damage, Free Radicals, Antioxidants.

HOW TO CITE THIS ARTICLE: Imam SN, Algaidi SA, Rahman Z. Recurrent spontaneous abortion and male factors: an overview. J. Evolution Med. Dent. Sci. 2016;5(71):5218-5223, DOI: 10.14260/jemds/2016/1182

\section{INTRODUCTION}

Half of the genetic material is contributed by male gamete and also plays a vital role in embryonic development. Genetic aberration in the sperm may therefore have important consequences on embryonic development and reproductive outcome. Till date semen analysis is the most widely relied tool to assess male fertility, ${ }^{1}$ but it is the modest predictor of fertility potential and reproductive outcome. $(2,3,4)$ Due to limited predictive potential of conventional semen analysis, new laboratory investigations are needed with better diagnostic values that can predict the adverse pregnancy outcome. New studies have revealed that tests for DNA fragmentation may be a better measure. $(2,5)$ The study of DNA fragmentation is the utmost important in era where advanced forms of assisted reproductive technologies are commonly used. Fertilisation of gametes and subsequent development depends on the integrity of DNA.(6,7) Recent studies have shown that there must be a threshold of sperm DNA fragmentation beyond, in which embryo development and pregnancy are impaired. $(8,9,10,11)$ It is now evidential that fragmented human sperm DNA may adversely affect reproductive potential of fertile men.(12)

Financial or Other, Competing Interest: None.

Submission 27-07-2016, Peer Review 20-08-2016,

Acceptance 26-08-2016, Published 03-09-2016.

Corresponding Author:

Dr. Zarin Rahman,

Department of Obstetrics \& Gynaecology,

National Medical College,

Birganj, Nepal.

E-mail:dr_zarin@yahoo.co.in

DOI: $10.14260 /$ jemds/2016/1182
It is also reported reduced functional competence of sperm with DNA fragmentation and reported a 3-fold increase in abortion rate in cases with high DNA fragmentation.(9,13-15) Risk for Recurrent Spontaneous Abortion (RSA) increases with age and parity, a woman of old reproductive age group is at greater risk of pregnancy loss than a younger age group women. The incidence of recurrent spontaneous abortion is approximately 1 in 300 pregnancies. However, epidemiologic studies have revealed that $1 \%$ to $2 \%$ of women experience recurrent spontaneous abortions.(16) About 15\% recognised pregnancies resulting in spontaneous loss; there are many more pregnancies that fail prior to being detected. According to one study, only $30 \%$ of all conception result in a live birth.(17)

\section{Causes of Recurrent Spontaneous Abortion}

There are several causes of RSA, important among them being anatomical uterine defects (Congenital uterine anomalies, intrauterine adhesions, uterine fibroids or polyps and cervical incompetence), genetic factors, infections, immunological and environmental factors and blood dyscrasias.(18-20) But despite extensive investigation of the female partner, a large number of cases (40-50\%) remain idiopathic.(21,22) It is possible that a number of such cases harbour sperm abnormalities. Till date evaluation of male factors in RSA only involves paternal chromosomal analysis and the role of sperm factors in RSA is totally ignored. With advent of advanced assisted micromanipulation procedures, the role of sperm factors is being realised. Till date about $40-60 \%$ RSA cases are identified as idiopathic. 


\section{Definition}

Recurrent Spontaneous Abortion (RSA), defined as 3 or more clinical pregnancy losses before the foetus has reached viability.(23)

There is general consensus that a diagnosis of RSA requires at least three consecutive miscarriages.(24)

\section{Incidence}

It is a frustrating condition that affects $1 \%$ of couples of childbearing age.(25) These values vary not only according to the population studied and the means of diagnosing the miscarriage, but also to the age and parity of the patient ( $4 \%$ at 20 years of age versus $16 \%$ after 35 years). These differences are greater if biochemical pregnancies are taken into account.

There are several causes of RSA, but despite detailed investigation 40 to $50 \%$ cases are idiopathic. Some of the main causes of RSA are discussed below.

\section{Anatomical Causes}

These include congenital uterine anomalies, intrauterine adhesions, uterine fibroids or polyps and cervical incompetence.

\section{Genetic Causes}

Approximately, 2-4\% of all cases of RSA are attributed to genetic causes associated with paternal chromosomal rearrangement like balanced reciprocal translocation (50\%), Robertsonian translocation (24\%) and inversions, insertions and mosaicism. Several couples also harbour single gene defects.

\section{Infectious Causes}

Certain infections like Listeria monocytogenes, Toxoplasma gondii, Rubella, Herpes Simplex Virus (HSV), Measles, Cytomegalovirus and Coxsackie viruses can cause RPL. There incidence is $0.5 \%$ to $5 \%$.

\section{Endocrine Causes}

Luteal Phase Defect (LPD), Polycystic Ovarian Syndrome (PCOS), uncontrolled diabetes mellitus, hypo- or hyperthyroidism and hyperprolactinemia are among the common causes of RSA. About 8-12\% of total cases of RPL are caused due to endocrinal disorder.(26)

\section{Immunological Causes}

One specific autoimmune disorder, Antiphospholipid Syndrome (APS) is associated with poor obstetric outcome including RSA.

\section{THROMBOTIC CAUSES}

\section{Environmental Causes}

Three particular environmental and lifestyle factors like smoking, alcohol and caffeine intake have gained particular attention and merit special consideration given their widespread use and modifiable nature. These factors are associated with elevated ROS levels. Radiation can also cause pregnancy loss; radiation above 5 rad is unsafe in pregnancy.

\section{Unexplained Causes}

In about $40-50 \%$ cases of RSA, no cause is identified and such cases are known as idiopathic miscarriage.

\section{Sperm DNA and its Compaction}

Sperm DNA is highly compact due to replacement of about $85 \%$ of histone by protamine.(27) This is to protect the sperm genome from external stress and degeneration by nucleases.(28) The $15 \%$ histone are still found at specific DNA sequence and at periphery in association with telomere ${ }^{(29,30)}$ and has less degree of compaction and may be involved in early human development. Infertile men are found to have increased histone ratio,(31) which causes poor compaction and make the sperm susceptible to external stress.

\section{Mitochondrial DNA Nucleotide Changes and Pregnancy Outcome \\ Dysfunctional mtDNA produce lower levels of ATP and higher levels of free radicals resulting in oxidative stress and oxidative stress is the chief cause of nuclear DNA damage. Paternal transmission of mitochondrial DNA is also reported, but these are degraded by 8 cell stage.(32) Kumar et al reported, oxidative stress increases mitochondrial nucleotide alterations and increased nuclear DNA damage. Such dysfunctional mitochondria results in hypospermatogenesis and production of sperm with impaired motility. This may be due to lower ATP levels and disorganised and partially formed microtubular apparatus.(33)}

\section{CAUSES OF SPERM DNA DAMAGE \\ Intrinsic Factors/Protamine Deficiency}

Protamine is a highly basic protein, which neutralises the negative charge of the DNA phosphodiester backbone and thus packages DNA into a crystalline compact structure, the size of which is $1 / 6-1 / 20$ that of any somatic cell genome.

An important subset of infertile men (about 5\%-15\%), possess complete protamine deficiency. The defective spermiogenesis could be due to DNA fragmentation and protamine deficiency.(34)

\section{ROS, Oxidative Stress and Sperm Function}

Reactive oxygen species are free radical having one or more unpaired electrons. The common free radical that play an important role in reproduction are superoxide, hydrogen peroxide, peroxyl and products of nitrogen.

The reproductive oxidative stress is due to imbalance of ROS production and its neutralisation by antioxidants. The major antioxidants that play an important role of neutralisation of ROS in the seminal fluid are glutathione, superoxide dismutase, reductase and peroxide.(35) A shift toward pro-oxidant may be due to more ROS production or low antioxidant are classified as oxidative stress.

Genital tract infection causes increase in leukocytes and level of ROS and subsequently initiates DNA damage.(36) Other infections like tuberculosis and pyrexia of unknown origin is also known to have increased ROS and subsequent initiation of DNA damage.

Febrile illness, certain lifestyle factors are associated with testicular hyperthermia which reported to cause increase in histone and protamine ratio and initiation of sperm DNA damage.(37-39)

It is found in the follicle stimulating hormone receptor knockout mice that low testosterone level is associated with high level of DNA damage.(40) 


\begin{abstract}
Abortive Apoptosis
Abortive apoptosis may result in sperm DNA damage, but this theory was previously challenged. It causes destruction of most of the spermatozoa during normal spermatogenesis. Sakkas et al reported that spermatozoa with damaged DNA have escaped apoptosis because of dysfunctional mitochondria. Germ cell apoptosis is found to be disrupted in people with old age and men with treatment on anticancer therapy.(40-43)
\end{abstract}

\section{Extrinsic Factors}

Cancer and cancer treatment, both chemo- and radiotherapy are associated with DNA damage and poor semen quality(44-47) and are strongly advised to have their sperm cryopreserved.(48)

Men with varicoceles are found to have high level of oxidative stress and associated damage of DNA(49); recently it is found that men with varicoceles there is abnormal retention of sperm cytoplasmic droplets and subsequent DNA damage. $(50,51)$

It has been reported by some studies that ROS level decreases rapidly in 1 week post-surgery, but significant sperm DNA integrity occurs only after 5-6 months postsurgery. $(52,53)$

Cigarette smoking: Abnormal semen parameters and DNA damage is reported in men who smoke regularly is probably due to testicular inflammation and activation of leukocytes leading to increased production of leukocyte derived ROS(54) and its level is significantly increased in these men.(55)

\section{Factors which can Decrease Sperm DNA Damage}

Lifestyle modification like quitting smoking, alcohol, minimising exposure to high temperature (Sauna, hot bath) and exposure to various pollutants, exercising in moderation, yoga, intake of fruits and vegetables can decrease oxidative stress and thus result in decrease in DNA damage.(36-39)

As local and systemic infection can cause increase in ROS levels and thereby causes significant DNA damage, such cases with high ROS level benefit immensely by treatment of infection, anti-inflammatory agents and antioxidant supplements. Recent studies have shown that vitamin $\mathrm{C}$ increases sperm concentration and vitamin $\mathrm{E}$ increases motility, but antioxidants should only be given to men with increased ROS levels since physiological ROS levels serve many important functions.(35) Varicocele is associated with high ROS levels and DNA damage and such cases benefit immensely by varicocelectomy.(50) Antioxidant can also be used in vitro in culture media in ART to prevent ROS mediated damage during spermiogenesis.

Thus there are several causes of RSA, but to understand if paternal factors play a causal role in a large fraction of cases identified as idiopathic is the aim of this study.

\section{DISCUSSION}

Recurrent spontaneous abortion is three or more consecutive pregnancy loss before 20 weeks of gestation.(56) Although some causes have been identified, still in $50 \%$ of couples the underlying mechanism (s) are not identified. It is possible that in large percentage of idiopathic cases, there is an underlying male factor which has been ignored and is the aetiology for recurrent pregnancy loss. These male factors are rarely studied or analysed in RSA.
Some studies have reported that sperm DNA damage may be associated with compromise of early embryonic development.(57,58) In case of RSA, the father is merely investigated for chromosomal trisomies in most of the centre and infertility and RSA are mainly considered to be due to an underlying female aetiology. Though chromosomal aberrations are the causal factor in $2-4 \%$ of cases experiencing RSA, approximately $2-4 \%$ of all cases of RSA are attributed to genetic causes associated with parental chromosomal rearrangement like balanced reciprocal translocation (50\%), Robertsonian translocation (24\%) and chromosomal inversions, insertions and mosaicism. It is emphasised that a number of cases may also have non-specific DNA damage and which cannot be detected by simple cytogenetic analysis and such DNA damage may result from oxidative stress.(59)

Oxidative stress is found to be one of the chief causes of DNA damage, which leads to sperm dysfunction and occurs due to imbalance between oxidant levels and antioxidant defence mechanism.

Sperm are highly vulnerable to oxidative stress as spermatozoal membrane is found to have high content of polyunsaturated fatty acid and low cytosolic antioxidants, as majority of cytoplasm is lost during spermiogenesis. Our body has both enzymatic and non-enzymatic antioxidants. Low levels of antioxidants and excess free radicals damage all biomolecules and reduce sperm functional competence. This is a protective mechanism, as such sperm are unable to fertilise the ova; however, if they are successful in fertilisation it may result in pre- or post-implantation losses.

A previous study(14) documented that infertile men with normal or abnormal sperm parameters have raised ROS levels and decreased antioxidant levels and high levels of nuclear DNA damage. However, it is difficult to predict increased ROS levels and DNA damage based on standard semen parameters. Thus, tests for seminal oxidative stress and DNA integrity are necessary to understand the reproductive potential of the sperm. Therefore, the attention has now shifted from analysing standard semen parameters to studying/evaluating molecular aspects of spermatozoa. Among these tests evaluating sperm DNA damage, free radical estimation, sperm transcript levels and telomere length are the focus of recent studies.

Oxidative stress and DNA damage is found in infertile men with normal or abnormal semen parameters(14) and so it is difficult to predict the DNA damage on the basis of standard semen parameters. Thus, tests for sperm oxidative stress and DNA damage are important to evaluate the sperm reproductive capacity. So the shift is from standard semen parameter to comprehensive evaluation of molecular aspect of sperm; among these tests are evaluating sperm DNA damage, estimation of free radicals and telomere length are focus of recent studies.

Polyunsaturated fatty of spermatozoa are highly vulnerable to ROS attack causing defective membrane permeability, ATP losses and subsequently sperm motility and morphology defects.(60,61) So this Lipid Peroxidation (LPO) apart from sperm membrane damage also causes DNA damage leading to infertility. ${ }^{(62)}$

Sperm DNA damage detected in infertile men are found to be associated with high ROS.(63) As observed in a pilot study that individuals with DFI $\geq 16.5$ have significantly impaired motility and morphology.(57) Dada et al reported that raised 
ROS levels lead to both mitochondrial sequence variation and nuclear DNA damage.(61) Mitochondrial sequence variation result in dysfunction of mitochondria, which generates less ATP and impairs motility, hypospermatogenesis and may also be the underlying pathology in infertility and RSA.(2) Since OS is an important factor for sperm DNA damage, it is postulated that it also induces sequence variation in mitochondria and thereby reducing ATP production, increased free radical generation and impairs motility of sperm and this is primary effect of mitochondrial dysfunction.

Now, it is established that sperm DNA fragmentation are associated with RPL and male infertility, but it is yet to be established that what is the threshold for DNA Fragmentation Index (DFI) which is associated with these effects of sperm DNA damage because the DFI threshold value of $16.50 \%(57)$ is found in the study in men of couple experiencing RPL. Another study reported low sperm DNA fragmentation (12\%) in the group that resulted in pregnancy than those that did not(64); but to further validate the threshold value from these studies large sample size is required. Negative correlation of sperm DNA fragmentation with fertilisation and embryo cleavage rate was reported.(65) However, no association of DNA fragmentation on IVF and ICSI outcome was found by TUNEL assay, but they observed high fertilisation rate in group with low DNA fragmentation $<10 \%$. Recent study by Dada et al reported that infertile men with repeated ICSI failure had increased sperm DNA fragmentation. Various studies documented SCSA as a reliable method for studying sperm chromatin integrity. Studies have reported threshold cut-off values of DFI between 20\%-30\% in infertile men opting for ART,(66-69) but in cases of iRSA the cut-off values by various methods of sperm DNA fragmentation assay have not been reported and the cut-off values also vary with the methods used for the sperm DNA integrity assessment and lacks standardised laboratory protocols. It has been reported that there is a 3 -fold increase in miscarriage rate in cases with high DNA fragmentation. This may be a mechanism of natural selection, whereby embryos with intact DNA integrity could only complete development. Recent studies have shown that sperm DNA damage correlates with infertility, early pregnancy loss, defective embryogenesis, congenital malformations, genetic abnormalities and decreased fecundity and DNA sperm methylation pattern.(70)

Till date majority of studies have focused on role of chromosomal abnormalities and analysis of nuclear genes for nucleotide alternations, which affect embryonic development. This study analyse role of oxidative stress, DNA damage and mitochondrial DNA variation in iRSA following spontaneous conception.

The role of OS and DNA damage in IRSA is an area deserving intense research. This is a preliminary genetic study which included analysis of sperm DNA damage, assessment of whole mtDNA sequence variation and assessment of ROS levels, which should be followed up by larger studies in different ethnic populations worldwide. This study aims to understand the role of ROS and nucleotide alterations in cases. Thus, a comprehensive genetic diagnostic workup in male partners is important in iRSA to understand exact aetiology, provide counselling and most adapted therapeutics to patients.

\section{CONCLUSION}

The role of OS and DNA damage in IRSA is an area deserving intense research. This is a preliminary genetic study, which included analysis of sperm DNA damage, assessment of whole mtDNA sequence variation and assessment of ROS levels, which should be followed up by larger studies in different ethnic populations worldwide. This study aims to understand the role of ROS and nucleotide alterations in cases. Thus, a comprehensive genetic diagnostic workup in male partners is important in iRSA to understand exact aetiology, provide counselling and most adapted therapeutics to patients.

\section{REFERENCES}

1. World Health Organization. WHO laboratory manual for the examination and processing of human semen and sperm-cervical mucus interaction. $5^{\text {th }}$ edn. Geneva, Switzerland 2010.

2. Shamsi MB, Venkatesh S, Pathak D, et al. Sperm DNA damage and oxidative stress in recurrent spontaneous abortion (RSA). Indian J Med Res 2011;133(5):550-1.

3. Bonde JP, Ernst E, Jensen TK, et al. Relation between semen quality and fertility: a population-based study of 430 first-pregnancy planners. The Lancet 1998;352(9135):1172-7.

4. Guzick DS, Overstreet JW, Factor-Litvak P, et al. Sperm morphology, motility and concentration in fertile and infertile men. N Engl J Med 2001;345(19):1388-93.

5. Venkatesh S, Singh A, Shamsi MB, et al. Clinical significance of sperm DNA damage threshold value in the assessment of male infertility. Reprod Sci 2011;18(10):1005-13.

6. Primakoff P, Myles DG. Penetration, adhesion and fusion in mammalian sperm-egg interaction. Science 2002;296(5576):2183-5.

7. Brewer LR, Corzett M, Balhorn R. Protamine-induced condensation and decondensation of the same DNA molecule. Science 1999;286(5437):120-3.

8. Ahmadi A, Ng SC. Fertilizing ability of DNA-damaged spermatozoa. J Exp Zool 1999;284(6):696-704.

9. Benchaib M, Lornage J, Mazoyer C, et al. Sperm deoxyribonucleic acid fragmentation as a prognostic indicator of assisted reproductive technology outcome. Fertil Steril 2007;87(1):93-100.

10. Morris LD, Llott S, Dixon L, et al. The spectrum of DNA damage in human sperm assessed by single cell gel electrophoresis (comet assay) and its relationship to fertilization and embryo development. Hum Reprod 2002;17(4):990-8.

11. Cho C, Jung-Ha H, Willis WD, et al. Protamine 2 deficiency leads to sperm DNA damage and embryo death in mice. Biol Reprod 2003;69(1):211-7.

12. Kodama H, Yamaguchi R, Fukuda J, et al. Increased oxidative deoxyribonucleic acid damage in the spermatozoa of infertile male patients. Fertil Steril 1997;68(3):519-24.

13. Henkel R, Hajimohammad $M$, Stalf $T$, et al. Influence of deoxyribonucleic acid damage on fertilization and pregnancy. Fertil Steril 2004;81(4):965-72.

14. Shamsi MB, Kumar R, Dada R. Evaluation of nuclear DNA damage in human spermatozoa in men opting for assisted reproduction. Indian Journal Medical Research 2008;127(2):115-23.

15. Frydman N, Prisant N, Hesters L, et al. Adequate ovarian follicular status does not prevent the decrease in pregnancy rates associated with high sperm DNA fragmentation. Fertil Steril 2008;89(1):92-7. 
16. Stephenson MD. Frequency of factors associated with habitual abortion in 197 couples. Fertil Steril 1996;66(1):24-9.

17. Macklon NS, Geraedts JP, Fauser BC. Conception to ongoing pregnancy: the black box of early pregnancy loss. Hum Reprod Update 2002;8(4):333-43.

18. Brown S. Miscarriage and its associations. Semin Reprod Med 2008;26(5):391-400.

19. Toth B, Jeschke U, Rogenhofer $N$, et al. Recurrent miscarriage: current concepts in diagnosis and treatment. J Reprod Immunol 2010;85(1):25-32.

20. McNamee K, Dawood F, Farquharson R. Recurrent miscarriage and thrombophilia: an update. Curr Opin Obstet Gynecol 2012;24(4):229-34.

21. Li T, Makris M, Tomsu M, et al. Recurrent miscarriage: aetiology, management and prognosis. Hum Reprod Update 2002;8(5):463-81

22. Branch DW, Gibson M, Silver RM. Clinical practice. Recurrent miscarriage. N Engl J Med 2010;363(18):17407.

23. Rai R, Regan L. Recurrent miscarriage. Lancet 2006;368(9535):601-11.

24. Hannes M, Englert $\mathrm{Y}$, Gotlieb W, et al. Recurrent spontaneous miscarriage. Rev Med Brux 1992;13(4):1036.

25. Porter TF, Scott JR. Evidence-based care of recurrent miscarriage. Best Pract Res Clin Obstet Gynaecol 2005;19(1):85-101.

26. Arredondo F, Noble LS. Endocrinology of recurrent pregnancy loss. Semin Reprod Med 2006;24(1):33-9.

27. Steger $K$, Pauls $K$, Klonisch $T$, et al. Expression of protamine-1 and -2 mRNA during human spermiogenesis. Mol Hum Reprod 2000;6(3):219-25.

28. Kosower NS, Katayose H, Yanagimachi R. Thiol-disulfide status and acridine orange fluorescence of mammalian sperm nuclei. J Androl 1992;13(4):342-8.

29. Gatewood JM, Cook GR, Balhorn R, et al. Sequence-specific packaging of DNA in human sperm chromatin. Science 1987;236(4804):962-4.

30. Gineitis AA, Zalenskaya IA, Yau PM, et al. Human sperm telomere-binding complex involves histone $\mathrm{H} 2 \mathrm{~B}$ and secures telomere membrane attachment. J Cell Biol 2000;151(7):1591-8.

31. Oliva R. Protamines and male infertility. Hum Reprod Update 2006;12(4):417-35.

32. Schwartz $M$, Vissing J. Paternal inheritance of mitochondrial DNA. N Engl J Med 2002;347(8):576-80.

33. Kumar M, Pathak D, Kriplani A, et al. Nucleotide variations in mitochondrial DNA and supra-physiological ROS levels in cytogenetically normal cases of premature ovarian insufficiency. Archives Gynecology Obstetrics 2010;282(6):695-705.

34. Carrell DT, Liu L, Peterson CM, et al. Sperm DNA fragmentation is increased in couples with unexplained recurrent pregnancy loss. Arch Androl 2003;49(1):49-55.

35. Sikka SC, Rajasekaran M, Hellstrom WJ. Role of oxidative stress and antioxidants in male infertility. J Androl 1995;16(6):464-8.

36. Erenpreiss J, Hlevicka S, Zalkalns J, et al. Effect of leukocytospermia on sperm DNA integrity: a negative effect in abnormal semen samples. J Androl 2002;23(5):717-23.
37. Sailer BL, Sarkar LJ, Bjordahl JA, et al. Effects of heat stress on mouse testicular cells and sperm chromatin structure. J Androl 1997;18(3):294-301.

38. Banks S, King SA, Irvine DS, et al. Impact of a mild scrotal heat stress on DNA integrity in murine spermatozoa. Reproduction 2005;129(4):505-14.

39. Jung A, Schill WB, Schuppe HC. Genital heat stress in men of barren couples: a prospective evaluation by means of a questionnaire. Andrologia 2002;34(6):349-55.

40. Xing W, Krishnamurthy H, Sairam MR. Role of follitropin receptor signaling in nuclear protein transitions and chromatin condensation during spermatogenesis. Biochem Biophys Res Commun 2003;312(3):697-701.

41. Sakkas D, Seli E, Bizzaro D, et al. Abnormal spermatozoa in the ejaculate: abortive apoptosis and faulty nuclear remodeling during spermatogenesis. Reprod Biomed Online 2003;7(4):428-32.

42. Brinkworth MH, Nieschlag E. Association of cyclophosphamide-induced male-mediated, foetal abnormalities with reduced paternal germ-cell apoptosis. Mutat Res 2000;447(2):149-54.

43. Singh NP, Muller CH, Berger RE. Effects of age on DNA double-strand breaks and apoptosis in human sperm. Fertil Steril 2003;80(6):1420-30.

44. Sailer BL, Jost LK, Erickson KR, et al. Effects of Xirradiation on mouse testicular cells and sperm chromatin structure. Environ Mol Mutagen 1995;25(1):23-30.

45. Fossa SD, De Angelis P, Kraggerud SM, et al. Prediction of post-treatment spermatogenesis in patients with testicular cancer by flow cytometric sperm chromatin structure assay. Cytometry 1997;30(4):192-6.

46. Morris ID. Sperm DNA damage and cancer treatment. Int J Androl 2002;25(5):255-61.

47. Lee SJ, Schover LR, Partridge AH, et al. American society of clinical oncology recommendations on fertility preservation in cancer patients. J Clin Oncol 2006;24(18):2917-31.

48. Saleh RA, Agarwal A, Sharma RK, et al. Evaluation of nuclear DNA damage in spermatozoa from infertile men with varicocele. Fertil Steril 2003;80(6):1431-6.

49. Fischer MA, Willis J, Zini A. Human sperm DNA integrity: correlation with sperm cytoplasmic droplets. Urology 2003;61(1):207-11.

50. Zini A, Blumenfeld A, Libman J, et al. Beneficial effect of microsurgical varicocelectomy on human sperm DNA integrity. Hum Reprod 2005;20(4):1018-21.

51. Zini A, Defreitas G, Freeman M, et al. Varicocele is associated with the abnormal retention of cytoplasmic droplets by human spermatozoa. Fertil Steril 2000;74(3):461-4.

52. Dada R, Mahfouz RZ, Kumar R, et al. A comprehensive work up for an asthenozoospermic man with repeated intracytoplasmic sperm injection (ICSI) failure. Andrologia 2011;43(5):368-72.

53. Potts RJ, Newbury CJ, Smith G, et al. Sperm chromatin damage associated with male smoking. Mutat Res 1999;423(1-2):103-11.

54. Tremellen K. Oxidative stress and male infertility-a clinical perspective. Human Reproduction Update 2008;14(3):243-58. 
55. Ford HB, Schust DJ. Recurrent pregnancy loss: etiology, diagnosis and therapy. Rev Obstet Gynecol 2009;2(2):7683.

56. Bellver J, Meseguer $\mathrm{M}$, Muriel L, et al. $\mathrm{Y}$ chromosome microdeletions, sperm DNA fragmentation and sperm oxidative stress as causes of recurrent spontaneous abortion of unknown etiology. Human Reprod 2010;25(7):1713-21.

57. Imam SN, Shamsi MB, Kumar K, et al. Idiopathic recurrent pregnancy loss: role of paternal factors: a pilot study. Journal Reproduction Infertility 2011;12(4):267-76.

58. Liu CJ, Wang AM, Shang W, et al. Sperm DNA damage and unexplained recurrent spontaneous abortion. Zhonghua Nan Ke Xue 2011;17(7):619-21.

59. De Lamirande E, Gagnon C. Reactive oxygen species and human spermatozoa. II. Depletion of adenosine triphosphate plays an important role in the inhibition of sperm motility. J Androl 1992;13(5):379-86.

60. Mahfouz R, Sharma R, Thiyagarajan A, et al. Semen characteristics and sperm DNA fragmentation in infertile men with low and high levels of seminal reactive oxygen species. Fertil Steril 2010;94(6):2141-6.

61. Kumar R, Venkatesh S, Kumar M, et al. Oxidative stress and sperm mitochondrial DNA mutation in idiopathic oligoasthenozoospermic men. Indian J Biochem Biophys 2009;46(2):172-7.

62. Irvine DS, Twigg JP, Gordon EL, et al. DNA integrity in human spermatozoa. relationships with semen quality. J Androl 2000;21(1):33-44.
63. Duran EH, Morshedi M, Taylor S, et al. Sperm DNA quality predicts intrauterine insemination outcome: a prospective cohort study. Hum Reprod 2002;17(2):31228.

64. Sun JG, Jurisicova A, Casper RF. Detection of deoxyribonucleic acid fragmentation in human sperm: correlation with fertilization in vitro. Biol Reprod 1997;56(3):602-7.

65. Larson-Cook KL, Brannian JD, Hansen KA, et al. Relationship between the outcomes of assisted reproductive techniques and sperm DNA fragmentation as measured by the sperm chromatin structure assay. Fertil Steril 2003;80(4):895-902.

66. Micinski P, Pawlicki K, Wielgus E, et al. The sperm chromatin structure assay (SCSA) as prognostic factor in IVF/IC SI program. Reprod Biol 2009;9(1):65-70.

67. Evenson DP, Jost LK, Marshall D, et al. Utility of the sperm chromatin structure assay as a diagnostic and prognostic tool in the human fertility clinic. Hum Reprod 1999;14(4):1039-49.

68. Evenson DP, Larson KL, Jost LK. Sperm chromatin structure assay: its clinical use for detecting sperm DNA fragmentation in male infertility and comparisons with other techniques. J Androl 2002;23(1):25-43.

69. Evenson DP, Kasperson K, Wixon RL. Analysis of sperm DNA fragmentation using flow cytometry and other techniques. Soc Reprod Fertil Suppl 2007;65:93-113.

70. Jenkins TG, Aston KI, Meyer TD, et al. Decreased fecundity and sperm DNA methylation patterns. Fertil Sterile 2016;105(1):51-7. 